\title{
Comparative Impact of Scintigraphic Parameters and B-Type Natriuretic Peptide for the Prediction of Major Cardiac Events in the QGS-Prognostic Value in the Elderly (Q-PROVE) Study
}

\author{
Yuko Igarashi, MD; Taishiro Chikamori, MD; Satoshi Hida, MD; Tadashi Nagao, MD; \\ Hirokazu Tanaka, MD; Yasuhiro Usui, MD; Tsuguhisa Hatano, MD; \\ Takayuki Morishima, MD; Hidefumi Yanagisawa, MD; Akira Yamashina, MD
}

\begin{abstract}
Background: Although B-type natriuretic peptide (BNP) has emerged as an important predictor for cardiac events, its effect on scintigraphic parameters is unknown.

Methods and Results: The Q-PROVE study is a multicenter study to evaluate the prognostic value of ECG-gated SPECT in 175 Japanese elderly patients. In addition, BNP was assessed in 102 patients. Outcome assessment included cardiac events and noncardiac deaths. Twelve elderly patients $(12 \%)$ had increased BNP $>130 \mathrm{pg} / \mathrm{ml}$. The summed stress score (SSS) was greater in patients with increased BNP than in those with normal BNP. Kaplan-Meier survival estimation indicated event-free survival rates at 3 years of $83 \%, 78 \%, 88 \%, 80 \%$, respectively, in patients with BNP $>130 \mathrm{pg} / \mathrm{ml}$, SSS $\geq 7$, summed difference score (SDS) $\geq 2$, and dilated end-diastolic volume (EDV), but $98 \%, 98 \%, 100 \%, 94 \%$ in those with BNP $\leq 130 \mathrm{pg} / \mathrm{ml}$, SSS $<7$, SDS $<2$ and normal EDV $(\mathrm{P}=0.006, \mathrm{P}=0.005, \mathrm{P}=0.0008, \mathrm{P}=0.01)$. Multivariate analysis demonstrated that an SDS was the only independent predictor for subsequent cardiac events (hazard ratio $=4.0, \mathrm{P}=0.04$ ).

Conclusions: Although BNP may have similar prognostic value to gated SPECT volumetric measurements in elderly patients with known or suspected coronary artery disease, myocardial ischemia as documented by SPECT is still indispensable for detecting high-risk patients compared with BNP alone. (Circ J 2009; 73: 1655-1660)
\end{abstract}

Key Words: B-type natriuretic peptide; Coronary artery disease; Elderly; Single-photon emission computed tomography

\begin{abstract}
A lthough B-type natriuretic peptide (BNP) has emerged as an important predictor not only for heart failure but also for myocardial ischemic events, ${ }^{1-4}$ its effect on scintigraphic parameters derived from single-photon emission computed tomography (SPECT) is unknown. We previously reported in the Quantitative gated SPECT Prognostic Value in the Elderly (Q-PROVE) study that stress myocardial SPECT successfully stratified the risk for subsequent cardiac events in 175 elderly patients with a mean age of 79 years..$^{5}$ In addition to the prognostic value of myocardial SPECT, therefore, we performed a post-hoc analysis of the Q-PROVE study to elucidate the prognostic value of BNP in elderly patients with known or suspected coronary artery disease (CAD).
\end{abstract}

\section{Methods}

\section{Subjects}

The Q-PROVE study initially enrolled 182 elderly patients aged 75-85 years from 11 institutions. ${ }^{5}$ Consecutive elderly patients who underwent gated SPECT in each institution for the evaluation of known or suspected CAD because of clinical symptoms, multiple coronary risk factors or abnormal ECG were eligible for enrollment. The following were the exclusion criteria: (1) age $<75$ years or $>85$ years, (2) acute heart failure, (3) atrial fibrillation, (4) acute myocardial infarction within 3 months before the SPECT study, (5) coronary revascularization within 3 months after the SPECT study, (6) serious concomitant hepatic or renal disease, (7) malignancy or any other illness with a poor prognosis. Of the 182 patients who participated in this study, 3 patients underwent coronary revascularization within 3 months after the SPECT study, and 4 patients were lost to follow-up. In addition, BNP was not measured within 3 months of the study in 73 patients, which left 102 patients for this post-hoc analysis.

\section{Study Protocol}

Applying the inclusion and exclusion criteria for the QPROVE study, patients were prospectively evaluated by primary physicians, cardiologists or both who were responsible for the SPECT study, and who assessed the past medical history including classical coronary risk factors. The patients underwent stress/rest myocardial perfusion

(Received March 9, 2009; revised manuscript received May 7, 2009; accepted May 13, 2009; released online July 28, 2009)

Department of Cardiology, Tokyo Medical University, Tokyo, Japan

Mailing address: Yuko Igarashi, MD, Department of Cardiology, Tokyo Medical University, 6-7-1 Nishi-Shinjuku, Shinjuku-ku, Tokyo 1600023, Japan. E-mail: yuko50@tokyo-med.ac.jp

All rights are reserved to the Japanese Circulation Society. For permissions, please e-mail: cj@j-circ.or.jp 
Short Axis

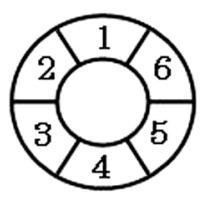

Distal

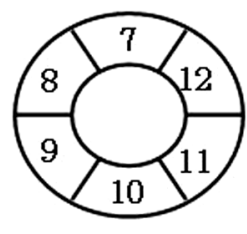

Mid

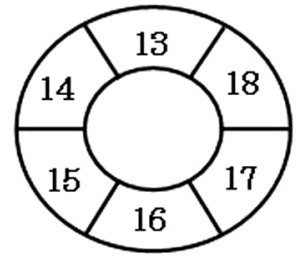

Basal
Vertical Long Axis

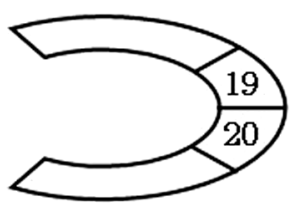

Figure 1. Assignment of myocardial segments for scoring of single-photon emission computed tomography images.

SPECT, and were followed up thereafter. The study protocol was approved by the ethical committee in each institution during the enrollment period since July 2001. All participants in this study gave informed consent.

\section{SPECT Imaging}

Each institution used 99mTc-sestamibi, stress/rest myocardial SPECT imaging according to its usual routine, either by exercise stress or by pharmacologic loading, and images were also analyzed in each institution as described previously. 6,7 The methods were those in routine use at each institution and the method of inducing stress was not particularly regulated. After induction of the stress, a digital gamma camera equipped with a multipurpose or low-energy high-resolution, parallel-hole collimator was rotated over a $180^{\circ}$ or $360^{\circ}$ arc. The acquisition time was $15-20 \mathrm{~min}$ for each patient. SPECT image processing was conducted on a dedicated nuclear medicine computer system using standard filters. Attenuation or scatter correction was not used.

According to the method reported by Berman et al, each SPECT image was divided into 20 segments (Figure 1). ${ }^{8}$ The myocardial uptake of $99 \mathrm{~m}$ Tc-sestamibi was visually evaluated by 2 experienced cardiologists within each institution, blinded to all clinical data, using a 5-grade scale: 0 (normal), 1 (slight reduction of uptake), 2 (moderate reduction of uptake), 3 (severe reduction of uptake) or 4 (absence of radioactive uptake). The score totals for all the segments during exercise and at rest were designated the summed stress scores (SSS) and the summed rest scores (SRS), respectively. The SSS minus SRS was defined as the summed difference score (SDS). ${ }^{8}$ In addition, each reconstructed short-axis ECG-gated SPECT image was processed by the quantitative gated SPECT program (Cedars-Sinai Medical Center, Los Angeles, CA, USA) developed by Germano et al, to automatically calculate the left ventricular end-diastolic volume, left ventricular end-systolic volume and left ventricular ejection fraction. ${ }^{9}$ In the volumetric and functional analyses, the cutoff value for normalcy was set according to gender. ${ }^{10}$ The cutoff points for end-diastolic volume, end-systolic volume, and ejection fraction were $88 \mathrm{ml}, 33 \mathrm{ml}$, and $63 \%$, respectively in men, and $59 \mathrm{ml}$, $17 \mathrm{ml}$, and $74 \%$, respectively in women. ${ }^{10}$ Disagreements in image interpretation, including every score for each SPECT segment, were resolved by consensus.

\section{Follow-up}

Patient follow-up was performed by each of the 11 study centers by physician contact or mailing to patients. The follow-up period was defined as the time from the SPECT study until a significant event or the last visit to each institution until the study period endpoint in April 2006.
Significant events were considered to be death, nonfatal myocardial infarction, percutaneous coronary intervention, coronary artery bypass grafting, malignant arrhythmias, or hospital admission because of heart failure or unstable angina, which were defined as described previously.11,12 All patients who were admitted to hospital because of heart failure required roentgenographic evidence of pulmonary congestion. Deaths were classified as either cardiac or noncardiac. Follow-up to event or death was ascertained in 102 of 102 patients by the endpoint of the study period.

\section{Statistical Analysis}

Results are expressed as means \pm SD. Student's t-test was used to compare the means of the continuous variables, and categorical variables were analyzed using the chi-square test. To determine a cutoff value of BNP and summed scores for subsequent prognosis, receiver-operating characteristic (ROC) curve analysis was performed. For survival analysis, Kaplan-Meier estimation using a log-rank test was performed. Multivariate analysis of outcome was assessed using the Cox proportional hazard model. A value of $\mathrm{P}<$ 0.05 was considered as statistically significant. Statistical analyses were performed using the SPSS-PC+ computation program (version 11.0, SPSS Inc, Chicago, IL, USA).

\section{Results}

\section{Overall Results}

The mean age of the 102 patients who completed follow-up was $79 \pm 3$ years; there were 59 men and 43 women. For stress SPECT, 35 patients (34\%) underwent exercise stress and the remaining $67(66 \%)$ had vasodilator pharmacologic loading. The left ventricular volumetric and functional measurements were successful in 100 patients $(98 \%)$, but could not be performed in the remaining 2 patients because of frequent extrasystoles.

A mean level of BNP was $73.5 \pm 137.7 \mathrm{pg} / \mathrm{ml}$ (3.4$1,310 \mathrm{pg} / \mathrm{ml})$. Weak but significant correlations were observed between BNP and SSS $(\mathrm{r}=0.32 ; \mathrm{P}=0.001)$, SRS $(\mathrm{r}=0.25 ; \mathrm{P}=0.001)$ and $\mathrm{SDS}(\mathrm{r}=0.22 ; \mathrm{P}=0.03)$. The ROC curve analysis revealed a BNP level of $130 \mathrm{pg} / \mathrm{ml}$ as the cutoff point for the prognosis of elderly patients in this cohort. Accordingly, using $130 \mathrm{pg} / \mathrm{ml}$ as the cutoff, the clinical characteristics of patients who had a high BNP level $(>130 \mathrm{pg} / \mathrm{ml})$ and those who had a low BNP level $(\leq 130 \mathrm{pg} / \mathrm{ml})$ are shown in Table 1. Age, gender, and the prevalence of classical coronary risk factors were similar in the 2 groups (Table 1). Although 40 patients (39\%) had had a previous myocardial infarction, coronary revascularization or both, the frequency of revascularization history was more common in patients with a high BNP level than in 
Table 1. Clinical Characteristics of 102 Elderly Patients With Known or Suspected Coronary Artery Disease

\begin{tabular}{lccc}
\hline & $\mathrm{BNP}>130 \mathrm{pg} / \mathrm{ml}(\mathrm{n}=12)$ & $\mathrm{BNP} \leq 130 \mathrm{pg} / \mathrm{ml}(\mathrm{n}=90)$ & P value \\
\hline M/F & $10 / 2$ & $49 / 41$ & $\mathrm{NS}$ \\
Age (years) & $80 \pm 2$ & $79 \pm 4$ & $\mathrm{NS}$ \\
Hypertension & $1(8 \%)$ & $16(18 \%)$ & $\mathrm{NS}$ \\
Hypercholesterolemia & $4(33 \%)$ & $43(48 \%)$ & $\mathrm{NS}$ \\
Diabetes mellitus & $5(42 \%)$ & $29(32 \%)$ & $\mathrm{NS}$ \\
$\quad$ Current smoker & $0(0 \%)$ & $9(10 \%)$ & $\mathrm{NS}$ \\
Remote history of revascularization & $6(50 \%)$ & $15(17 \%)$ & 0.02 \\
PCI & $0(0 \%)$ & $6(7 \%)$ & $\mathrm{NS}$ \\
CABG & $5(42 \%)$ & $22(24 \%)$ & $\mathrm{NS}$ \\
Remote history of MI & & \\
\hline
\end{tabular}

BNP, B-type natriuretic peptide; PCI, percutaneous coronary intervention; CABG, coronary artery bypass grafting; MI, myocardial infarction.

Table 2. Scintigraphic Data According to BNP Level

\begin{tabular}{lccc}
\hline & BNP $>130 \mathrm{pg} / \mathrm{ml}(\mathrm{n}=12)$ & BNP $\leq 130 \mathrm{pg} / \mathrm{ml}(\mathrm{n}=90)$ & $\mathrm{P}$ value \\
\hline End-diastolic volume $(\mathrm{ml})$ & $120 \pm 74$ & $75 \pm 31$ & $\mathrm{NS}$ \\
End-systolic volume $(\mathrm{ml})$ & $73 \pm 70$ & $34 \pm 22$ & $\mathrm{NS}$ \\
Ejection fraction $(\%)$ & $47 \pm 17$ & $57 \pm 13$ & 0.01 \\
Summed stress score & $17.7 \pm 14.6$ & $8.0 \pm 8.3$ & 0.04 \\
Summed rest score & $14.9 \pm 15.1$ & $7.4 \pm 7.8$ & NS \\
Summed difference score & $2.8 \pm 5.1$ & $0.6 \pm 3.8$ & NS \\
\hline
\end{tabular}

BNP, B-type natriuretic peptide.

Table 3. Comparison of Clinical Characteristics of Patients With and Without Cardiac Events

\begin{tabular}{lccc}
\hline & Cardiac event $(+)(\mathrm{n}=14)$ & Cardiac event $(-)(\mathrm{n}=88)$ & P value \\
\hline M/F & $10 / 4$ & $49 / 39$ & NS \\
Age (years) & $80 \pm 3$ & $79 \pm 4$ & NS \\
Hypertension & $3(21 \%)$ & $14(16 \%)$ & NS \\
Hypercholesterolemia & $5(36 \%)$ & $42(48 \%)$ & NS \\
Diabetes mellitus & $5(36 \%)$ & $29(33 \%)$ & NS \\
Smoking & $5(36 \%)$ & $29(33 \%)$ & NS \\
BNP $>130$ pg/ml & $6(43 \%)$ & $6(7 \%)$ & 0.001 \\
Medications & & & \\
ACEI/ARB & $6(43 \%)$ & $39(43 \%)$ & NS \\
$\beta$-blockers & $0(0 \%)$ & $2(2 \%)$ & NS \\
CCBs & $9(64 \%)$ & $56(64 \%)$ & NS \\
Diuretics & $3(21 \%)$ & $9(10 \%)$ & NS \\
Statins & $4(29 \%)$ & $38(43 \%)$ & NS \\
Aspirin & $9(64 \%)$ & $56(64 \%)$ & NS \\
Warfarin & $1(7 \%)$ & $7(8 \%)$ &
\end{tabular}

BNP, B-type natriuretic peptide; ACEI, angiotensin-converting enzyme inhibitor; ARB, angiotensin-receptor blocker; CCBs, calcium-channel blockers.

those with a low level (Table 1). ECG-gated SPECT showed that the SSS was greater in patients with a high BNP level than in those with a low BNP level. Although the ejection fraction was lower in patients with a high BNP level than in those with a low BNP level, end-diastolic volume, end-systolic volume, SRS, and SDS were similar in the 2 groups (Table 2).

During a mean follow-up of $3.4 \pm 0.6$ years (median, 3.8 years), 17 patients had significant events, of whom 3 patients died from noncardiac causes, and the remaining 14 patients had cardiac events: cardiac death in 2, heart failure that needed hospital admission in 4, percutaneous coronary intervention in 6 , coronary artery bypass grafting in 1 , unstable angina in 1 . The clinical characteristics of patients who subsequently had cardiac events and those who were free of cardiac events are shown in Table 3. Age, gender, the prevalence of classical coronary risk factors and medications were similar in patients with and without cardiac events, although patients with a high BNP level were more frequently observed among those with cardiac events than among those without (Table 3). ECG-gated SPECT showed that end-diastolic volume, SSS and SDS were greater in patients with cardiac events than in those without, whereas end-systolic volume, ejection fraction and SRS were similar in the 2 groups (Table 4 ).

\section{BNP, Gated SPECT and Prognosis}

Kaplan-Meier survival estimation was performed based on a BNP with a cutoff of $130 \mathrm{pg} / \mathrm{ml}$. The cardiac event-free survival rate in patients with a low BNP level was $99 \%$ at 1 year and $98 \%$ at 3 years, which was higher than the $100 \%$ at 1 year and $83 \%$ at 3 years in patients with a high BNP level $(\mathrm{P}=0.006$, log-rank $=7.7)$ (Figure 2A).

To analyze the SPECT data, the cutoff values were set according to ROC curve analysis as follows: 7 for the SSS, 3 for the SRS and 2 for the SDS. In addition, gender-spe- 
Table 4. Comparison of Scintigraphic Parameters of Patients With and Without Cardiac Events

\begin{tabular}{lccc}
\hline & Cardiac event $(+)(\mathrm{n}=14)$ & Cardiac event $(-)(\mathrm{n}=88)$ & P value \\
\hline End-diastolic volume $(\mathrm{ml})$ & $119 \pm 70$ & $74 \pm 30$ & 0.04 \\
End-systolic volume $(\mathrm{ml})$ & $68 \pm 63$ & $34 \pm 23$ & $\mathrm{NS}$ \\
Ejection fraction $(\%)$ & $50 \pm 15$ & $57 \pm 13$ & $\mathrm{NS}$ \\
Summed stress score & $16.4 \pm 12.3$ & $8.0 \pm 8.7$ & 0.002 \\
Summed rest score & $11.8 \pm 11.4$ & $7.7 \pm 8.8$ & $\mathrm{NS}$ \\
Summed difference score & $4.6 \pm 6.3$ & $0.3 \pm 3.1$ & $<0.0001$ \\
\hline
\end{tabular}

(A)

(\%)

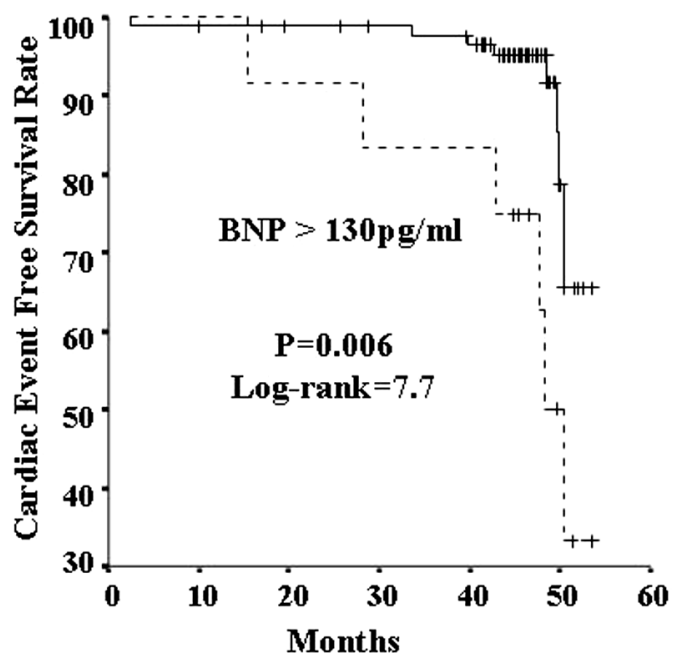

(B)

(\%)

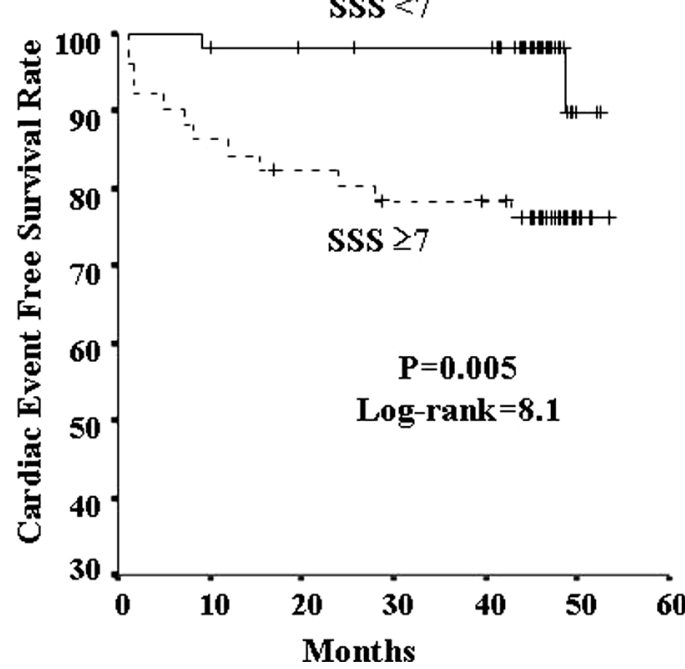

Figure 2. Kaplan-Meier survival estimates for cardiac events according to B-type natriuretic peptide (BNP). (A) Patients with BNP $\leq 130 \mathrm{pg} / \mathrm{ml}$ ( $\mathrm{n}=90$; solid line), and patients with $\mathrm{BNP}>130 \mathrm{pg} / \mathrm{ml}$ ( $\mathrm{n}=12$; dashed line). A significant difference was found between these 2 groups $(\mathrm{P}=0.006$ by log-rank test). Kaplan-Meier survival estimates for cardiac events according to the summed stress score (SSS). (B) Patients with SSS $<7$ ( $\mathrm{n}=51$; solid line), and patients with SSS $\geq 7$ $(\mathrm{n}=51$; dashed line). A significant difference was found between these 2 groups $(\mathrm{P}=0.005$ by log-rank test).

(A)

(\%)

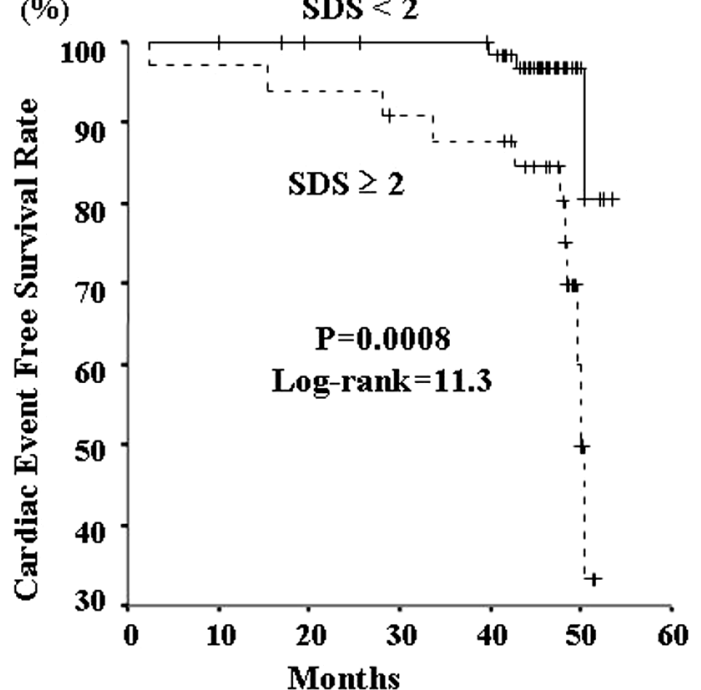

(B)

(\%)

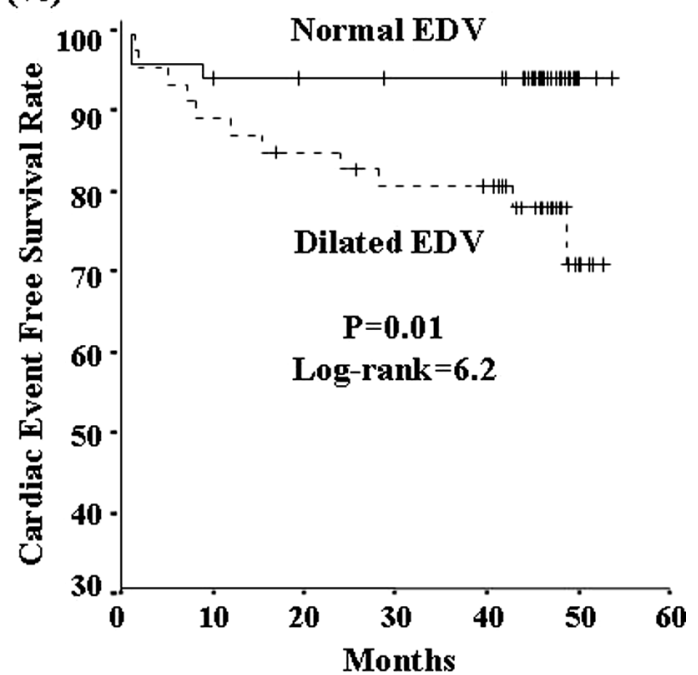

Figure 3. Kaplan-Meier survival estimates for cardiac events according to the summed difference score (SDS). (A) Patients with SDS $<2$ ( $n=69$; solid line), and patients with $\operatorname{SDS} \geq 2(n=33$; dashed line). A significant difference was found between these 2 groups ( $\mathrm{P}=0.0008$ by log-rank test). Kaplan-Meier survival estimates for cardiac events according to enddiastolic volume (EDV) as assessed by gated SPECT. (B) Patients with normal EDV ( $\mathrm{n}=53$; solid line), and patients with dilated $\operatorname{EDV}(\mathrm{n}=47$; dashed line). A significant difference was found between these 2 groups $(\mathrm{P}=0.01$ by $\log$-rank test). 
Table 5. Predictors for Cardiac Events by the Cox Proportional Hazard Model

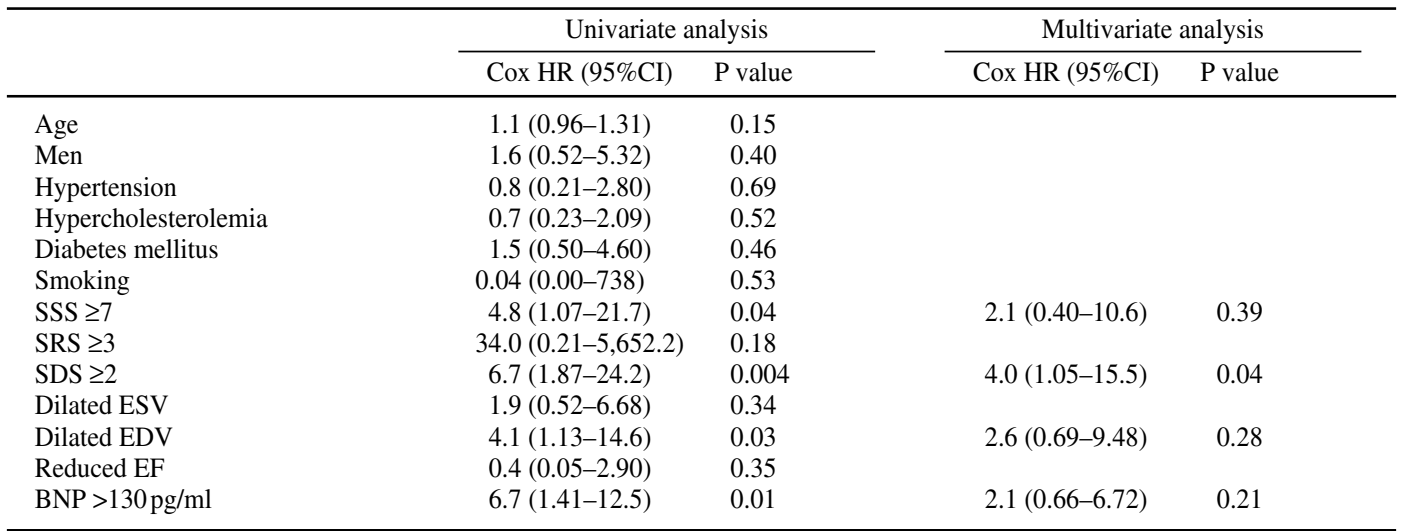

HR, hazard ratio; CI, confidence interval; SSS, summed stress score; SRS, summed rest score; SDS, summed difference score; ESV, end-systolic volume; EDV, end-diastolic volume; EF, ejection fraction; BNP, B-type natriuretic peptide.

cific normalcy for the volumetric analysis derived from the J-ACCESS database was applied..$^{10}$ Kaplan-Meier survival curves, which showed statistical significance by the univariate analyses, are shown in Figures $\mathbf{2}$ and $\mathbf{3}$. The cardiac event-free survival rate in patients with a SSS $<7$ was $98 \%$ at 1 year and $98 \%$ at 3 years, which was higher than the $85 \%$ at 1 year and $78 \%$ at 3 years in those with a SSS $\geq 7$ $(\mathrm{P}=0.005$, log-rank $=8.1$ ) (Figure 2B). The cardiac eventfree survival rate in patients with a SDS $<2$ was $100 \%$ at 1 year and $100 \%$ at 3 years, which was also significantly higher than the $97 \%$ at 1 year and $88 \%$ at 3 years in those with a $\mathrm{SDS} \geq 2(\mathrm{P}=0.0008, \log$-rank $=11.3)$ (Figure 3A). Kaplan-Meier survival estimates revealed that the cardiac event-free survival rate in patients with normal end-diastolic volume was $94 \%$ at 1 year and $94 \%$ at 3 years, which was higher than the $87 \%$ at 1 year and $80 \%$ at 3 years in those with dilated end-diastolic volume $(\mathrm{P}=0.01, \log$-rank $=6.2)$ (Figure 3B).

\section{Predictors of Cardiac Events}

Thirteen variables related to clinical and scintigraphic findings (Tables 3,4) were considered potential predictors for the occurrence of subsequent cardiac events during followup, and were included in the multivariate analysis using the Cox proportional hazard model. The analysis revealed that only SDS $\geq 2$ was an independent predictor of cardiac events (hazard ratio $(\mathrm{HR})=4.0, \mathrm{P}=0.04$ ) (Table 5). The analysis was repeated without setting a cutoff point in order to exclude a potential confounding effect in the process of selecting the cutoff points. The BNP and SPECT data were included in the Cox proportional hazard model as numerical variables and the analysis again showed that the SDS was the only independent predictor for subsequent cardiac events $(\mathrm{HR}=1.1, \mathrm{P}=0.04)$.

\section{Discussion}

Since the discovery of BNP, the measurements of this left ventricular-derived peptide for the management of patients with heart failure has become routine clinical practice. ${ }^{14-18}$ Furthermore, recent studies showed that the BNP level predicted subsequent prognosis not only in patients with heart failure but also in those with CAD. 1,3,4 In the present posthoc analysis of the Q-PROVE study, a high BNP level $>130 \mathrm{pg} / \mathrm{ml}$ was significantly associated with subsequent cardiac events in 102 elderly patients with known or suspected CAD. The cardiac event-free survival rate in patients with a high BNP level was $83 \%$ at 3 years, which was lower than the $98 \%$ at 3 years in patients with a low BNP level (Figure 2A). When the patient population of the current study consisting of 102 elderly patients with a mean age of 79 years is taken into consideration, BNP may have a clinical role in risk stratification even in elderly patients aged 75 years or more who are suspected of having CAD.

In the prognostication and risk stratification of patients with known or suspected CAD, nuclear cardiology is providing accumulating evidence applicable to daily practice. ${ }^{19-21}$ In the present study, gated SPECT also showed event-free survival rates at 3 years of $78 \%, 88 \%$, and $80 \%$, respectively, in patients with a SSS $\geq 7$, SDS $\geq 2$, and dilated end-diastolic volume, but 98\%, 100\%, and 94\%, respectively in those with a SSS $<7$, SDS $<2$ and normal enddiastolic volume (Tables 3-5). Thus, elderly patients with normal or mildly abnormal myocardial perfusion and normal left ventricular volume have a good prognosis. These observations are consistent with previous reports. ${ }^{22-25}$ To compare the prognostic impact of BNP with scintigraphic parameters, both BNP and scintigraphic parameters were evaluated by multivariate analysis. The Cox proportional hazard model revealed that the SDS was the only independent predictor of outcomes (Table 5). Thus, although BNP may have a similar prognostic value to scintigraphic parameters in elderly patients with known or suspected CAD, myocardial ischemia as documented by SPECT is still indispensable for better detection of high-risk patients.

Normalcy for the BNP level differs according to age, gender and other factors. ${ }^{26}$ In this study based on elderly patients aged 75 years or more, a cutoff point of $130 \mathrm{pg} / \mathrm{ml}$ was determined by ROC curve analysis and was higher than the BNP level for heart failure in middle-aged patients. ${ }^{15}$ The left ventricular volumetric analysis as assessed by gated SPECT showed larger end-diastolic and end-systolic volumes in patients with a high BNP level than in those with a low BNP level, though this did not reach statistical significance because of the wide variation of these measurements. In contrast, the left ventricular ejection fraction was reduced significantly in patients with a high BNP level. These observations are consistent with previous studies in which the BNP level was increased in elderly subjects and/or those with impaired left ventricular systolic function. $1,27,28$ 
In addition, BNP showed weak but significant correlations with scintigraphic summed scores. However, the best correlation was observed between BNP and the SSS, which represents the combination of myocardial scar and stressinduced ischemia. Previous studies reported significant increase in the BNP level after stress myocardial SPECT, particularly in those in whom myocardial ischemia was documented.29,30 Therefore, it is reasonable that the 2 markers, which are influenced not only by cardiac function but also by myocardial ischemia, showed a good relationship.

Although our results indicate the superiority in prognostic value of stress myocardial SPECT to BNP in elderly patients with suspected CAD, the current study was a posthoc analysis of the Q-PROVE study. Thus, these preliminary results need confirmation through a series of largescale, prospective clinical trials.

\section{Conclusion}

Although BNP may have a similar prognostic value to gated SPECT volumetric measurements in elderly patients with known or suspected CAD, myocardial ischemia as documented by SPECT is still indispensable for better detection of high-risk patients compared with BNP alone.

\section{Acknowledgments}

We gratefully acknowledge the contribution of all patients and the work done by all the Q-PROVE investigators and participating centers. The QPROVE study was supported in part by a grant from Daiichi Radioisotope Laboratories Ltd, Tokyo, Japan. A complete list of all Q-PROVE investigators has been published by Nagao et al. ${ }^{5}$

\section{References}

1. Kragelund C, Gronning B, Kober L, Hildebrandt P, Steffensen R. $\mathrm{N}$-terminal pro-B-type natriuretic peptide and long-term mortality in stable coronary heart disease. N Engl J Med 2005; 352: 666-675.

2. Domingo KB, Ansari M, Schiller NB, Massie B, Whooley MA. B-type natriuretic peptide and ischemia in patients with stable coronary disease: Data from the Heart and Soul Study. Circulation 2003; 108: $2987-2992$.

3. OmLand T, Richards AM, Wergeland R, Vik-Mo H. B-Type natriuretic peptide and long-term survival in patients with stable coronary artery disease. Am J Cardiol 2005; 95: 24-28.

4. Richards M, Nicholls MG, Espiner EA, Lainchbury JG, Troughton RW, Elliott J, for the Christchurch Cardioendocrine Research Group and the Australia-New Zealand Heart Failure Group. Comparison of B-type natriuretic peptides for assessment of cardiac function and prognosis in stable ischemic heart disease. J Am Coll Cardiol 2006; 47: $52-60$.

5. Nagao T, Chikamori T, Hida S, Igarashi Y, Kuwabara Y, Nishimura S, et al. Quantitative gated single-photon emission computed tomography with $99 \mathrm{mTc}$ sestamibi predicts major cardiac events in elderly patients with known or suspected coronary artery disease. Circ J 2007; 71: $1029-1034$

6. Hida S, Chikamori T, Usui $\mathrm{Y}$, Yanagisawa H, Morishima $\mathrm{T}$, Yamashina A, et al. Effect of percutaneous coronary angioplasty on myocardial perfusion, function, and wall thickness as assessed by quantitative gated single-photon emission computed tomography. Am J Cardiol 2003; 91: 591-594.

7. Tanaka H, Chikamori T, Hida S, Usui Y, Harafuji K, Igarashi $Y$, et al. Comparison of post-exercise and post-vasodilator stress myocardial stunning as assessed by electrocardiogram-gated single-photon emission computed tomography. Circ J 2005; 69: 1338-1345.

8. Berman DS, Hachamovitch R, Kiat H, Cohen I, Cabico JA, Wang $\mathrm{FD}$, et al. Incremental value of prognostic testing in patients with known or suspected ischemic heart disease: A basis for optimal utilization of exercise technetium-99m sestamibi myocardial perfusion single-photon emission computed tomography. J Am Coll Cardiol 1995; 26: 639-647.

9. Germano G, Kiat H, Kavanagh PB, Moriel M, Mazzanti M, Su HT, et al. Automatic quantification of ejection fraction from gated myocardial perfusion SPECT. J Nucl Med 1995; 36: 2138-2147.
10. Nakajima K, Kusuoka H, Nishimura S, Yamashina A, Nishimura T. Normal limits of ejection fraction and volumes determined by gated SPECT in clinically normal patients without cardiac events: A study based on the J-ACCESS database. Eur J Nucl Med 2007; 34: 10881096.

11. The Task Force on Heart Failure of the European Society of Cardiology. Guidelines for the diagnosis of hear failure. Eur Heart J 1995; 16: $741-751$.

12. Braunwald E, Jones RH, Mark DB, Brown J, Brown L, Cheitlin MD, et al. Diagnosing and managing unstable angina. Circulation 1994; 90: $613-622$.

13. Schnabel R, Lubos E, Rupprecht HJ, Espinola-Klein C, Bickel C, Lackner KJ, et al. B-type natriuretic peptide and the risk of cardiovascular events and death in patients with stable angina: Results from the AtheroGene study. J Am Coll Cardiol 2006; 47: 552-558.

14. Cowie MR, Struthers AD, Wood DA, Coats AJ, Thompson SG, Poole-Wilson PH, et al. Value of natriuretic peptides in assessment of patients with possible new heart failure in primary care. Lancet 1997; 350: $1349-1353$.

15. Maisel AS, Krishnaswamy P, Nowak RM, McCord J, Hollander JE, Duc P, et al. Breathing Not Properly multinational study investigators: Rapid measurement of B-type natriuretic peptide in the emergency diagnosis of heart failure. N Engl J Med 2002; 347: 161-167.

16. Lainchbury JG, Campbell E, Frampton CM, Yandle TG, Nicholls MG, Richards AM. Brain natriuretic peptide and n-terminal brain natriuretic peptide in the diagnosis of heart failure in patients with acute shortness of breath. J Am Coll Cardiol 2003; 42: 728-735.

17. Mueller C, Scholer A, Laule-Kilian K, Benedict Martina BC, Schindler $\mathrm{C}$, Buser $\mathrm{P}$, et al. Use of B-type natriuretic peptide in the evaluation and management of acute dyspnea. N Engl J Med 2004; 350: 647-654.

18. Takahashi N, Yamamoto A, Tezuka S, Ishikawa M, Abe J, Aminani $\mathrm{K}$, et al. Assessment of left ventricular dyssynchrony during development of heart failure by a novel program using ECG-gated myocardial perfusion SPECT. Circ J 2008; 72: 370-377.

19. Beller GA, Zaret BL. Contributions of nuclear cardiology to diagnosis and prognosis of patients with coronary artery disease. Circulation 2000; 101: $1465-1478$.

20. Klocke FJ, Baird MG, Lorell BH, Bateman TM, Messer JV, Berman DS, et al. ACC/AHA/ASNC Guidelines for the clinical use of cardiac radionuclide imaging. J Am Coll Cardiol 2003; 42: 1318-1333.

21. Sharir T, Germano G, Kang X, Lewin HC, Miranda R, Cohen I, et al. Prediction of myocardial infarction versus cardiac death by gated myocardial perfusion SPECT: Risk stratification by the amount of stress-induced ischemia and the poststress ejection fraction. $J$ Nucl Med 2001; 42: 831-837.

22. Valeti US, Miller TD, Hodge DO, Gibbons RJ. Exercise singlephoton emission computed tomography provides effective risk stratification of elderly men and elderly women. Circulation 2005; 111: 1771- 1776 .

23. Kawamura M, Ohta Y, Katoh K, Nishimura S. Medium- to long-term prognostic impact of dipyridamole thallium-201 myocardial singlephoton emission computed tomography in elderly patients. Circ $J$ 2003; 67: 913-917.

24. Winter OD, Velghe A, de Veire NV, Bondt PD, Buyzere MD, De Wiele $\mathrm{CV}$, et al. Incremental prognostic value of combined perfusion and function assessment during myocardial gated SPECT in patients aged 75 years or older. J Nucl Cardiol 2005; 12: 662-670.

25. Kusuoka H, Nishimura S, Yamashina A, Nakajima K, Nishimura T, for the J-ACCESS investigators. Surveillance study for creating the national clinical database related to ECG-gated myocardial perfusion SPECT of ischemic heart disease: J-ACCESS study design. Ann Nucl Med 2006; 20: 195-202.

26. Ishino M, Takeishi Y, Niizeki T, Watanabe T, Nitobe J, Miyamoto T, et al. Risk stratification of chronic heart failure patients by multiple biomarkers. Circ J 2008; 72: 1800-1805.

27. Groenning BA, Nilsson JC, Sondergaard L, Pedersen F, Trawinski J, Baumann M, et al. Detection of left ventricular enlargement and impaired systolic function with plasma N-terminal pro brain natriuretic peptide concentrations. Am Heart J 2002; 143: 923-929.

28. Eggers KM, Lindahl B, Venge P, Lind L. B-type natriuretic peptides and their relation to cardiovasucular structure and function in a population-based sample of subjects. Am J Cardiol 2009; 103: 1032-1038.

29. Foote RS, Pearlman JD, Siegel AH, Yeo KT. Detection of exerciseinduced ischemia by changes in B-type natriuretic peptides. $J$ Am Coll Cardiol 2004; 474: $1980-1987$.

30. Sabatine MS, Morrow DA, de Lemos JA, OmLand T, Desai MY, Tanasijevic M, et al. Acute changes in circulating natriuretic peptide levels in relation to myocardial ischemia. J Am Coll Cardiol 2004; 44: $1988-1995$ 